Article

\title{
Spaceborne EO and a Combination of Inverse and Forward Modelling for Monitoring Lava Flow Advance
}

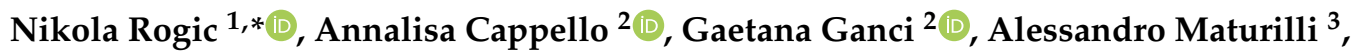 \\ Hazel Rymer ${ }^{1}$, Stephen Blake ${ }^{1}$ and Fabrizio Ferrucci ${ }^{1,4}$ \\ 1 School of Environment, Earth and Ecosystem Sciences, The Open University, Milton Keynes MK7 6AA, UK; \\ hazel.rymer@open.ac.uk (H.R.); stephen.blake@open.ac.uk (S.B.); fabrizio.ferrucci@open.ac.uk (F.F.) \\ 2 Istituto Nazionale di Geofisica e Vulcanologia, Osservatorio Etneo, 95125 Catania, Italy; \\ annalisa.cappello@ingv.it (A.C.); gaetana.ganci@ingv.it (G.G.) \\ 3 German Aerospace Center, (DLR), Institute of Planetary Research, 12489 Berlin, Germany; \\ alessandro.maturilli@dlr.de \\ 4 Department of Environmental and Chemical Engineering, University of Calabria, 87036 Rende (CS), Italy \\ * Correspondence: nikola.rogic@open.ac.uk; Tel.: +44-77-313-02424
}

Received: 1 November 2019; Accepted: 13 December 2019; Published: 16 December 2019

\begin{abstract}
We aim here to improve the understanding of the relationship between emissivity of the lava and temperature by carrying out a multi-stage experiment for the $2017 \mathrm{Mt}$ Etna (Italy) eruption. We combine laboratory, spaceborne, and numerical modelling data, to quantify the emissivity-temperature relationship. Our laboratory-based Fourier-transform infrared (FTIR) results indicate that emissivity and temperature are inversely correlated, which supports the argument that emissivity of molten material is significantly lower than that of the same material in its solid state. Our forward-modelling tests using MAGFLOW Cellular Automata suggest that a 35\% emissivity variation (0.95 to 0.60 ) can produce up to $46 \%$ overestimation (for constant emissivity 0.60 ) in simulated/forecasted lava flow lengths (compared to actual observed). In comparison, our simulation using a 'two-component' emissivity approach (i.e., different emissivity values for melt and cooled lava) and constant emissivity 0.95 compares well ( $\leq 10 \%$ overestimation) with the actual 2017 lava flow lengths. We evaluated the influence of variable emissivity on lava surface temperatures using spaceborne data by performing several parametrically controlled assessments, using both constant ('uniform') and a 'two-component' emissivity approach. Computed total radiant fluxes, using the same spaceborne scene (Landsat 8 Operational Land Imager (OLI)), differ $\leq 15 \%$ depending on emissivity endmembers (i.e., 0.95 and 0.60 ). These results further suggest that computed radiant flux using high-spatial resolution data is bordering at lower boundary (range) values of the moderate-to-high temporal resolution spaceborne data (i.e., Moderate Resolution Imaging Spectroradiometer (MODIS) and Spinning Enhanced Visible and Infrared Imager (SEVIRI)), acquired for the same target area (and the same time interval). These findings may have considerable impact on civil protection decisions made during volcanic crisis involving lava flows as they approach protected or populated areas. Nonetheless, the laboratory work, reported here, should be extended to include higher volcanic eruptive temperatures (up to $1350 \mathrm{~K}$ ).
\end{abstract}

Keywords: remote sensing; volcanic hazard modelling; emissivity uncertainty; FTIR spectroscopy; Mount Etna 


\section{Introduction}

A small fraction of the active subaerial volcanoes around the world are monitored regularly [1]. There is variety in local practices used for volcano surveillance [2,3], and fewer than $10 \%$ of the potentially active volcanoes worldwide (erupted at least once in the last 10,000 years) are monitored with the appropriate quality, frequency, and timeliness [1,4]. This poses an objective and significant threat to communities [5], especially in countries lacking in infrastructure and with limited financial resources [6], creating a critical gap in hazard assessment and risk management [7].

Satellite remote sensing is an established technological solution for bridging critical gaps in volcanic hazard and risk mitigation, as it offers cost effective and global volcano surveillance at a wide range of spatial and temporal resolutions [8-10]. It can significantly contribute to operational eruption forecasting and hazard assessment [11-15].

Remote sensing offers the potential of gathering valuable data without the risks and the cost associated with ground-based volcanic fieldwork. None of the spaceborne sensors to date, such as the low-to-moderate spatial resolution Moderate Resolution Imaging Spectroradiometer (MODIS) onboard Terra and Aqua satellites, Spinning Enhanced Visible and Infrared Imager (SEVIRI) onboard the Meteosat Second Generation (MSG) geostationary platform, or the higher spatial resolution Landsat 8 OLI (Operational Land Imager), were designed specifically to observe volcanic thermal emission during effusive eruptions. Nonetheless, some of these sensors have the ability to record high-temperature surface anomalies, such as those that occur during volcanic effusive activity. The thermal emission of an active volcanic surface relates directly to the volcanic activity at a specific time and can be detected and measured from space to identify physical processes occurring on the ground.

All objects above absolute zero $(0 \mathrm{~K})$ emit electromagnetic radiation at a wavelength and intensity that are functions of the characteristics of the surface temperature and emissivity (radiating efficiency). Therefore, there is a direct relationship between thermal emissions and thermal volcanic activity. According to the Stefan-Boltzmann law, the radiance emitted by the surface will increase, as the temperature of the surface rises. As a hotter volcanic surface will radiate more energy and higher radiant flux density, any variation observed radiance will reflect a variation in volcanic activity on the ground. Sensors having channels in the mid-infrared (MIR) and thermal infrared (TIR) bands (e.g., MODIS) have been used widely for decades to detect volcanic thermal anomalies [16,17] and have proven to be a valuable tool for identifying trends and monitoring volcanic activity [18-25]. On the other hand, sensors such as the Multi-Spectral Imager (MSI) aboard Sentinel-2 satellites and OLI, having channels in the short-wave infrared (SWIR), and providing data at medium-high spatial resolution, enable a better identification of high-temperature thermal anomalies (e.g., lava flows) [23,26]. This approach is explored further in this study, using high-spatial resolution data (Landsat 8 OLI).

Satellite data analysis and interpretation rely on certain assumptions and input parameters, some of which, such as emissivity, are not well quantified for molten and hot volcanic rocks. Several recent thermal emission studies of silicate glasses and basaltic lava [27] suggest that the emissivity of molten material is significantly lower than that of the same material in its solid state. Thus, emissivity is not only wavelength dependent but also temperature dependent $[25,28]$.

The computation of surface temperature from spaceborne data and models that rely on computed temperatures to track cooling with time, introduce errors due to uncertainties in emissivity as an input parameter. It has been recognized previously [24] that an uncertainty in emissivity gives rise to errors in pixel-integrated temperatures (i.e., lava surface temperatures) that may consequently affect estimates of total and maximum radiant fluxes. The need to quantify the emissivity-temperature relationship, often neglected in both spaceborne and modelling applications was illustrated using 'distance-to-run' forecasts for the $2001 \mathrm{Mt}$ Etna eruption [28]. A recent study investigating the application of thermo-rheological models to forecast lava flow emplacement, used a 'two-component' emissivity model [25], assuming the fraction of molten lava and cooled crust. The study concluded that the emissivity of molten lava may be as low as 0.60 , while an emissivity of 0.95 corresponded to the crusted fraction of the lava. 
The motivation for the present study is to assess the role of emissivity in the determination of radiant fluxes obtained from spaceborne data. To achieve this, we compared the results from spaceborne data with models using three approaches; firstly by applying a constant 'standard' emissivity, where an assumed value (e.g., 0.95) is applied to the entire thermal anomaly; secondly by applying a constant but lower value for emissivity (0.60), known to be more appropriate for molten lava temperatures; and thirdly we applied a modification of the 'two-component' emissivity approach [25], by applying a specific emissivity parameterization ( 0.60 for melt and 0.95 for crust).

Mt Etna (Sicily, Italy) was chosen as a perfect candidate for this study due to its persistent activity, displaying a range of eruptive products and styles $[29,30]$ and the availability of spaceborne data with a range of temporal and spatial resolutions. Considering that it is surrounded by almost one million people, the implications of volcanic activity monitoring are significant for civil protection and urban planning in the region.

Out of several significant, long- [31] and short-lived [29] effusive events on Mt Etna, the most recent, longest eruptive episode (Figure 1) started from the old "saddle" ( $\left.\mathrm{V}_{1}\right)$ between the South-East Crater (SEC) and the New Southeast Crater (NSEC) on the morning of 15 March 2017 and continued from a pit crater, opening on the south flank of the saddle $\left(\mathrm{V}_{2}\right)$. The lava flow expanded to both southeast and southwest, diverted by the eruptive cones formed during the 2002-2003 flank eruption. At the beginning of April 2017, the lava started flowing from two ephemeral vents that opened downstream $\left(\mathrm{V}_{3}\right.$ and $\left.\mathrm{V}_{4}\right)$. This eruption, which ended on 9 April 2017, emitted $7.96 \times 10^{6} \mathrm{~m}^{3}$ of lava [8] over an area of $1.782 \mathrm{~km}^{2}$ (Figure 1).

The location and chemical composition of collected samples (filled blue circles) for the $2017 \mathrm{Mt}$ Etna eruption are shown in Figure 1 and Table 1, respectively.

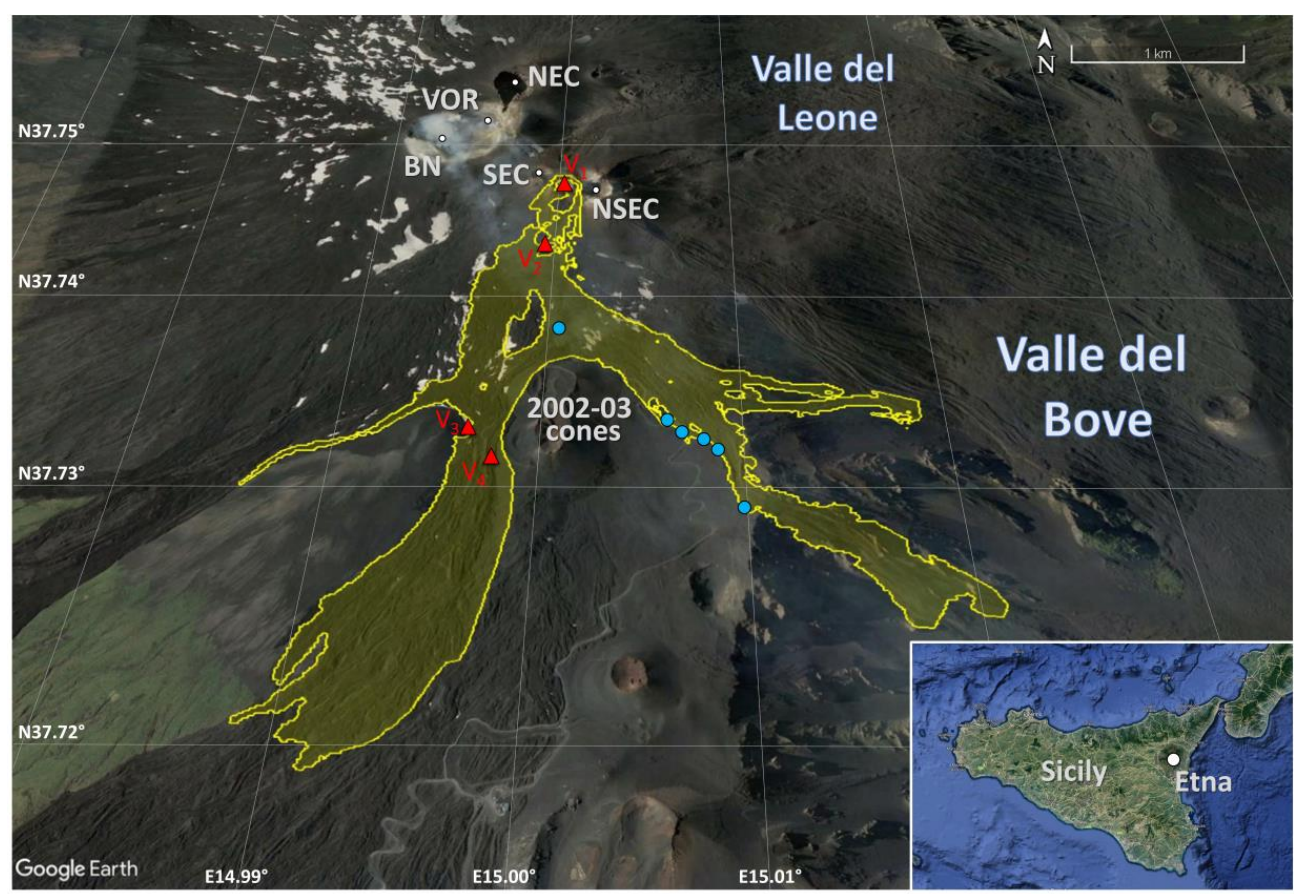

Figure 1. Main Figure: Google Earth three-dimensional (3D) view (from south) of Etna's summit area. The active craters are indicated, North-East Crater (NEC), Voragine (VOR), Bocca Nuova (BN), South-East Crater (SEC), and New South-East Crater (NSEC), together with the 2002-2003 cones that diverted the lava flow emitted by the March-April 2017 eruption. "Valle del Leone" is the NE part of Valle del Bove, a large horseshoe-shaped depression located on the eastern side of the volcano. The location and opening times (see text) of the 2017 eruptive vents are indicated by filled red triangles, and the location of collected samples (NRE.1S) by filled blue circles. The actual lava flow field (in yellow) was retrieved from the Sentinel-2A image acquired on 8 April 2017. Inset: Location of Mt Etna volcano on the island of Sicily, Italy. 
Table 1. X-ray fluorescence (XRF) major elements content, as a component oxide weight percent (wt $\%)$ for the NRE.1 Series (NRE.1S).

\begin{tabular}{llllllllllll}
\hline $\mathrm{SiO}_{2}$ & $\mathrm{TiO}_{2}$ & $\mathrm{Al}_{2} \mathrm{O}_{3}$ & $\mathrm{Fe}_{2} \mathrm{O}_{3}$ & $\mathrm{MnO}$ & $\mathbf{M g O}$ & $\mathrm{CaO}$ & $\mathrm{Na}_{2} \mathrm{O}$ & $\mathbf{K}_{2} \mathrm{O}$ & $\mathbf{P}_{2} \mathrm{O}_{5}$ & LOl & Total \\
\hline 47.49 & 1.63 & 17.71 & 11.26 & 0.17 & 4.81 & 10.362 & 3.65 & 1.72 & 0.55 & -0.35 & 99.02 \\
\hline
\end{tabular}

\section{Materials and Methods}

\subsection{Rock Samples}

To measure the emissivity of the exposed 2017 lava flow, we collected six rock samples (Figure 1; Table 1), termed NRE.1 Series (NRE.1S). These were initially investigated using Fourier transform infrared (FTIR) spectroscopy, to derive absolute emissivity from radiance at a range of temperatures (400-900 K) and wavelengths (5.0-15.0 $\mu \mathrm{m})$.

Bulk chemical analyses of major elements for the NRE.1S samples were processed using X-ray fluorescence (XRF) technique (Table 1). XRF results indicate silica $\left(\mathrm{SiO}_{2}\right)$ and alkali $\left(\mathrm{Na}_{2} \mathrm{O}+\mathrm{K}_{2} \mathrm{O}\right)$ content of 47.49 and 5.37, respectively. This is consistent with previous research on Etnean lavas [32], categorizing them as basalts to transitional trachy-basalts.

\subsection{Laboratory-Based Data Acquisition}

\subsubsection{Emissivity from Surface Radiance Spectra}

Thermal emission spectra of the samples were measured at the Planetary Spectroscopy Laboratory (PSL) of the German Aerospace Center (DLR) in Berlin, in a vacuum (0.7 mbar), over a temperature range of 400-900 K, in the 5.0 to $15.0 \mu \mathrm{m}$ wavelength range. The experimental set up $[33,34]$ uses an external 'simulation chamber', attached to the FTIR spectrometer (Figure 2), measuring the emissivity of solid crushed samples (grain size 1000-3000 $\mu \mathrm{m}$ ). The emissivity chamber is equipped with an internal webcam and several temperature sensors to measure the sample/cup temperature, monitor the equipment, and record chamber temperatures. Both the cup and the sample are heated uniformly by induction, and the temperature of the emitting surface is measured using a thermophile sensor in contact with the surface. The resulting data are calibrated using the emissivity spectrum of the blackbody material [34] to provide the set of absolute emissivity data.

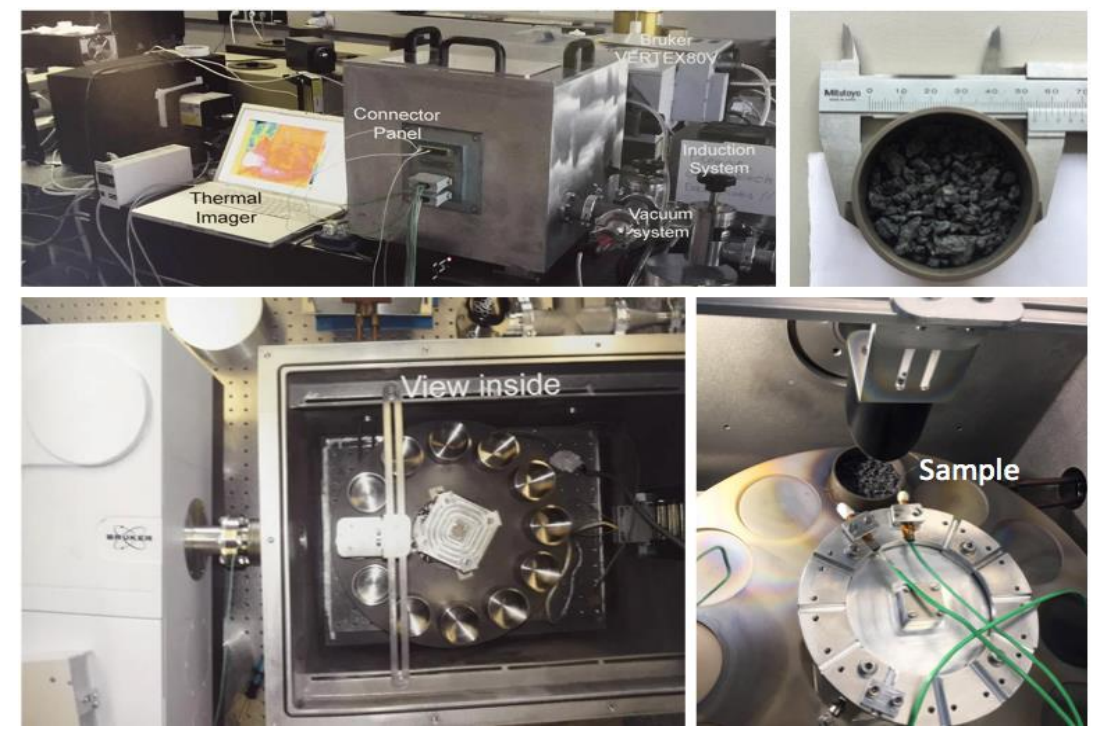

Figure 2. Experimental set up ([34] and this study) to measure emissivity of the NRE.1S, using Bruker VERTEX $80 \mathrm{~V}$ instrument. 


\subsection{Thermal Surveillance Using Spaceborne Data}

\subsubsection{High-Spatial Resolution Data}

In this study, we selected a platform hosting decametric resolution sensors operating at the time of the 2017 Mt Etna eruption: the Landsat 8 (Landsat Continuity Mission), launched by National Aeronautics and Space Administration (NASA) in April 2013. Landsat 8 hosts two payloads, the Operational Land Imager (OLI) and the Thermal Infrared Sensor (TIRS), with the overall capability of collecting data in 11 spectral bands $(0.44-12.00 \mu \mathrm{m}), 30 \mathrm{~m}$ to $100 \mathrm{~m}$ spatial resolution global coverage, and equatorial repeat cycle of 16 days [35].

General aspects of physics and techniques of thermal remote sensing of active volcanoes can be found in [22] among others. Here, we used the specific approach described in [23]. The mean spectral radiance measured by a satellite sensor as a digital number (DN) can be converted into 'at-satellite' spectral radiance $R_{\lambda}\left(W m^{-2} \mu m^{-1} s r^{-1}\right)$, which is composed of the surface reflected radiance $\left(R_{\lambda, D}\right)$, the upwelling path radiance $\left(R_{\lambda, U}\right)$ and the surface thermal radiance $L(\lambda, T)$

$$
\begin{aligned}
R_{\lambda} & =\tau_{\lambda} L(\lambda, T)+\tau_{\lambda} \rho_{\lambda} R_{\lambda, D}+R_{\lambda, U} \\
& =R_{\lambda, \text { thermal }}+R_{\lambda, \text { nonthermal }}
\end{aligned}
$$

where, $\tau_{\lambda}$ is the atmospheric spectral transmission coefficient; $\rho_{\lambda}$ is the spectral reflectivity of the target; $R_{\lambda, \text { thermal }}$ is composed of $\tau_{\lambda} L(\lambda, T)$ and $R_{\lambda \text {, nonthermal }}$ is composed of $\tau_{\lambda} \rho_{\lambda} R_{\lambda, D}+R_{\lambda, U}$.

The upwelling path radiance $\left(R_{\lambda, U}\right)$ contribution in the short wavelength infrared (SWIR) region, such as in OLI's Band $6(1.60 \mu \mathrm{m})$ and Band $7(2.20 \mu \mathrm{m})$ was very low, so it was ignored and the radiation reflected by the surface $\left(R_{\lambda, D}\right)$ in daytime images were estimated by subtracting the mean spectral radiance $\left(R_{\lambda}\right)$ value of surrounding nonthermally anomalous pixels, from the thermally anomalous pixels. If available, the nighttime images would be preferable, as they contain only the thermal component. However, in this study, we analysed all available daytime images acquired during the 2017 Mt Etna Eruption, distributed by the Global Visualization (GloVis) Viewer [36].

The overall spectral radiance $L_{\lambda}$, emitted by a blackbody at a particular temperature $(\mathrm{T})$ and wavelength $(\lambda)$, is given by Planck's radiation law. This quantifies Wien's displacement law which states that the spectral radiance emitted from a surface will increase with temperature while at the same time, the highest emissions will become of shorter wavelength.

Based on Planck's radiation law, the spectral radiance of a pixel (Equation (2)) is a function of its integrated temperature $\left(T_{i}\right)$ :

$$
\mathrm{L}(\lambda, \mathrm{T})=\frac{\varepsilon_{\lambda} \mathrm{c}_{1} \lambda^{-5}}{\pi\left[\exp \left(\frac{\mathrm{c}_{2}}{\lambda \mathrm{T}_{\mathrm{i}, \lambda}}\right)-1\right]}
$$

where, $c_{1}$ and $c_{2}$ are related constants; $c_{1}=1.19 \times 10^{-16} \mathrm{~W} \mathrm{~m}^{-2} \mathrm{sr}^{-1}$ and $c_{2}=1.44 \times 10^{-2} \mathrm{~m} \mathrm{~K}$, respectively. $c_{1}=2 \pi h c_{2}$ where $h$ is Planck's constant and $\mathrm{c}$ is the speed of light; $c_{2}=h \frac{c}{k}$ where k is the Stefan-Boltzmann constant; $\lambda$ is the wavelength in micrometers; $\varepsilon_{\lambda}$ is the emissivity of the radiative surface, and $T_{i, \lambda}$ is the integrated pixel temperature at a specific wavelength.

Assuming that the pixel was thermally pure (i.e., isothermal surface), the pixel integrated temperature $\left(T_{i}\right)$ should be the temperature of the target surface after being corrected for emissivity, atmospheric, and sensor response effects. However, a scene recorded over an active lava flow surface may contain a wide range of temperatures (and emissivities), so a single pixel will be a mixture of several thermal components. Therefore, after radiometric and atmospheric data correction [37-39], and following procedures outlined in [23], the fundamentals of 'dual-band' approaches [20,24,40-43] were employed using unsaturated radiance data in SWIR (OLI's Bands 6 and 7) to derive an effective temperature $\left(T_{e}\right)$ for each radiant pixel of the high-temperature thermal anomaly analysed:

$$
\mathrm{T}_{\mathrm{e}}=\left[\mathrm{f}_{\mathrm{h}} \mathrm{T}_{\mathrm{h}}^{4}+\left(1-\mathrm{f}_{\mathrm{h}}\right) \mathrm{T}_{\mathrm{c}}^{4}\right]^{\frac{1}{4}}
$$


In the case of high-spatial resolution spaceborne data, pixel radiance values can be computed as the weighted average of subpixel radiance emitted by two distinctly different temperature components: the hot component at temperature $T_{h}$ representing melt, occupying a surface fraction $f_{h}$ of the pixel and the cooler, crusted component, at temperature $T_{c}$ occupying the remainder of the pixel (i.e., $1-f_{h}$ ).

Having obtained the effective temperature $\left(T_{e}\right)$ for each radiant pixel by solving sub-resolutions [23], the remotely sensed radiant heat flux $\left(Q_{R_{-} \text {calc }}\right)$ was acquired $[23,44,45]$ :

$$
Q_{R_{c} \text { calc }}=A \varepsilon \sigma \tau\left(T_{e}^{4}-T_{a}^{4}\right)
$$

where, $A$ is the pixel surface area; $\varepsilon$ is emissivity; $\sigma$ is the Stefan-Boltzmann constant; $\tau$ is atmospheric transmissivity, and $T_{e}^{4}$ is the effective temperature to the fourth power, and the $T_{a}^{4}$ is the ambient temperature to the fourth power.

The retrieval of radiant heat flux (power) for the thermally anomalous pixels using high-spatial resolution spaceborne radiance data was calculated using two OLI's SWIR bands (Band 6 located at $1.65 \mu \mathrm{m}$ and B7 at $2.20 \mu \mathrm{m}$ central wavelengths) and these radiance values, extracted from thermally anomalous pixels, were used to compute total radiant flux values for each scene analysed.

Total radiant fluxes were computed by applying constant emissivity values (i) 0.95 and (ii) 0.60 , uniformly to the entire thermal anomaly, and (iii) using a 'two-component' emissivity approach by creating a 'threshold' within the thermal anomaly, based on pixel radiance values for assumed cooler crust radiant pixels $(\varepsilon=0.95)$ and for assumed melt $(\varepsilon=0.60)$. Landsat 8 OLI's Band 7 recorded radiance values were used to create 'thresholds', based on sensor's minimum and maximum operating limits [46], minimum radiance value selected was 5.0 (to exclude background radiance) and maximum radiance selected was 32.00 ( maximum radiance in Band 7). Assumed crust (5.0-24.99) and assumed melt (25.00-32.00) radiance limits were applied in our 'two-component' emissivity computation.

\subsubsection{Moderate-to-High Temporal Resolution Data}

Moderate-to-high temporal resolution satellite data were processed using the HOTSAT thermal monitoring system $[47,48]$. In particular, the system ingests MODIS data, which provides images at 1 $\mathrm{km}$ spatial resolution up to four times per day and SEVIRI data, which enables almost continuous monitoring (i.e., four times per hour and up to a 5 min sampling interval in rapid scanning service mode) with a spatial resolution of $3 \mathrm{~km}$ at nadir. The system is designed to automatically provide the location of the 'hotspot' pixels, if present, and to quantify their thermal anomaly by computing the associated radiant heat flux.

The algorithm implemented in HOTSAT firstly detects clouds in the analysed images, by applying the texton technique [49], then looks for thermal anomalies by using a contextual approach. An adaptive threshold is retrieved in a 'non-active volcanic' portion of the image to be analysed and a potential 'hotspot' pixel is found if the threshold is overcome in the 'volcanic' portion of the image. Those potential 'hotspot' pixels are then classified as a true 'hotspot' after successfully passing several statistical tests.

The radiant heat flux is computed for all the pixels classified as a true 'hotspot'. This is accomplished by using the MIR radiance method [50], where the radiant heat flux is computed by approximating the Planck law in MIR to the 4th order power law, thus obtaining:

$$
Q_{M I R}=\frac{A_{\text {sampl }} \varepsilon \sigma}{a \varepsilon_{M I R}} L_{M I R, h}
$$

where, $Q_{M I R}$ is the radiant heat flux $(\mathrm{W}), A_{\text {sampl }}$ is the ground sampling area $\left(\mathrm{m}^{2}\right), \varepsilon$ is the emissivity, $\sigma$ is the Stefan-Boltzmann constant $\left(5.67 \times 10^{-8} \mathrm{~J} \mathrm{~s}^{-1} \mathrm{~m}^{-2} \mathrm{~K}^{-4}\right), L_{M I R, h}$ and $\varepsilon_{M I R}$ are the hot pixel spectral radiance and surface spectral emissivity in the appropriate MIR spectral band. The constant $a\left(\mathrm{~W} \mathrm{~m}^{-4}\right.$ $\left.\mathrm{sr}^{-1} \mu \mathrm{m}^{-1} \mathrm{~K}^{-4}\right)$ is determined from empirical best-fit relationships. This approach may introduce errors larger than $30 \%$ outside a range of temperatures $\sim 600-1500 \mathrm{~K}$, where that approximation holds [50]. 
According to this formulation, the value of emissivity is considered equal to the emissivity in the MIR and it is usually simplified. So, emissivity has no impact on the $Q_{M I R}$ computation if it is the assumed constant ( 0.95 or 0.60 ) and wavelength independent. However, if we consider that emissivity can vary with wavelength, Equation (5) cannot be reduced, and the emissivity values in MIR $\left(\varepsilon_{M I R}\right)$ and the total emissivity $(\varepsilon)$ should be taken into account. Based on recent work [51-53], we assumed that the total variation of $\varepsilon_{M I R}$ with respect to $\varepsilon$, is $\pm 45 \%$.

The total radiant heat flux, obtained summing up the $Q_{M I R}$ for the hotspot pixels of each image, was then converted into time averaged discharge rate (TADR) according to [54].

\subsection{Numerical Modelling Approach}

\subsubsection{MAGFLOW}

To forward model the lava flow path of the 2017 Mt Etna eruption, we used the latest version of MAGFLOW, which has been implemented on graphic processing units (GPUs) using CUDA (Compute Unified Device Architecture), a parallel computing architecture provided by NVIDIA for the deployment of the latest generation of GPUs as high-performance parallel computing hardware [13,55]. Thanks to its fast execution, MAGFLOW on GPU [13] has become the core of the satellite-driven modelling strategy 'Lav@Hazard' for the production of real-time eruptive scenarios and the forecasting of lava flow hazards [54,56,57].

For the 2017 Mt Etna eruption, we ran MAGFLOW using the HOTSAT-derived TADRs on a 5 $m$ digital elevation model (DEM) of Mt Etna derived from a tri-stereo Pléiades imagery acquired on 18 July 2016 [58,59]. The three-dimensional (3D) processing of the tri-stereo Pléiades imagery was performed using the free and open source MicMac photogrammetric library [60], developed by the French Institut Géographique National.

The location and opening times of the eruptive vents $\left(V_{1}, V_{2}, V_{3}\right.$, and $\left.V_{4}\right)$ are reported in Figure 1. Given the chemical composition of the lava (Table 1), we used the typical properties of Mt Etna's basaltic rocks (density $=2600 \mathrm{~kg} / \mathrm{m}^{3}$; specific heat capacity $=1150 \mathrm{~J} \mathrm{~kg}^{-1} \mathrm{~K}^{-1}$; solidification temperature $=1173 \mathrm{~K}$; extrusion temperature $=1360 \mathrm{~K}$ ), while varying the emissivity to assess the impact on the final emplacement of the lava flow. We ran three MAGFLOW simulations: two with a static, constant emissivity value ( 0.60 or 0.95$)$ and another with a temperature-dependent emissivity (i.e., 'two- components': 0.60 for molten lava and 0.95 for cooled crust).

\section{Results}

\subsection{Emissivity from Radiance}

Spectral signatures for the NRE.1S samples (Figure 3) obtained using thermal emission FTIR are consistent and comparable with previous laboratory-based research of basaltic rocks [61] and Etnean lavas [28]. This clearly demonstrates that emissivity is not only wavelength, but also temperaturedependent, as measured emissivity decreases with every temperature increase step (400-900 K). However, this trend could not be observed clearly between 5.0-6.0 $\mu \mathrm{m}$. This is because of the instrument sensitivity limitations. Emissivity spectral curves at low-to-moderate temperatures (400-700 K) show a maximum variation of $\leq 0.0074$. However, a considerably larger decrease in emissivity $(\leq 0.0346)$ occurs at moderate-to-high temperature $(700-900 \mathrm{~K})$. The emissivity decrease with temperature increase does not appear to be linear. The maximum measured emissivity variation between 400 and $900 \mathrm{~K}$ is $\leq 0.0377$ (at $11.8 \mu \mathrm{m}$ ), which may suggest that emissivity would tend to decrease more substantially with any further temperature increase. 
'True' Emissivity variation with temperature (400-900 K) for NRE.1S

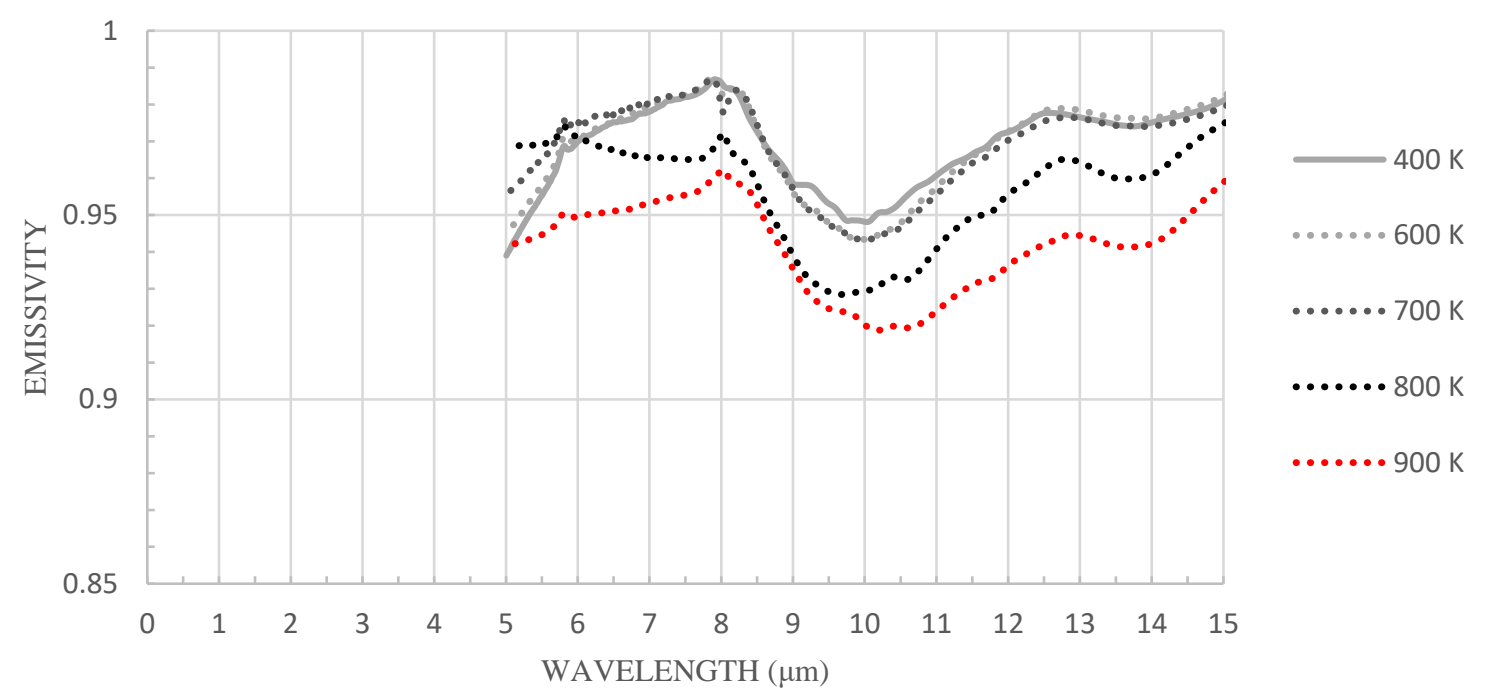

Figure 3. Emissivity spectral signatures for NRE.1S at 400-900 K and 5.0-15.0 $\mu \mathrm{m}$, using thermal emission Fourier-transform infrared spectroscopy (FTIR).

An additional 'cooling test' was performed by measuring emissivity of the same series in the opposite direction (cooling), by decreasing temperature steps (i.e., 900-400 K), while maintaining consistent sample conditions. The deviance in emissivity values during the temperature increase (heating), shown in Figure 3 and the temperature decrease (cooling) was $\leq 0.0050$ with no hysteresis deviation trend in either direction.

For a direct comparison with spaceborne data and to obtain a clearer emissivity trend with temperature, laboratory-measured FTIR emissivity results are shown at Landsat 8 TIR wavelengths (Figure 4). Emissivity values at $10.80 \mu \mathrm{m}$ are lower $(\geq 0.02)$ than those at $12.00 \mu \mathrm{m}$, displaying steady negative trend(s) at both wavelengths with temperature increase at $400-700 \mathrm{~K}$ and more significant decrease at 700-900 K.

NRE.1S Emissivity variation with Temperature at Landsat 8 TIR bands

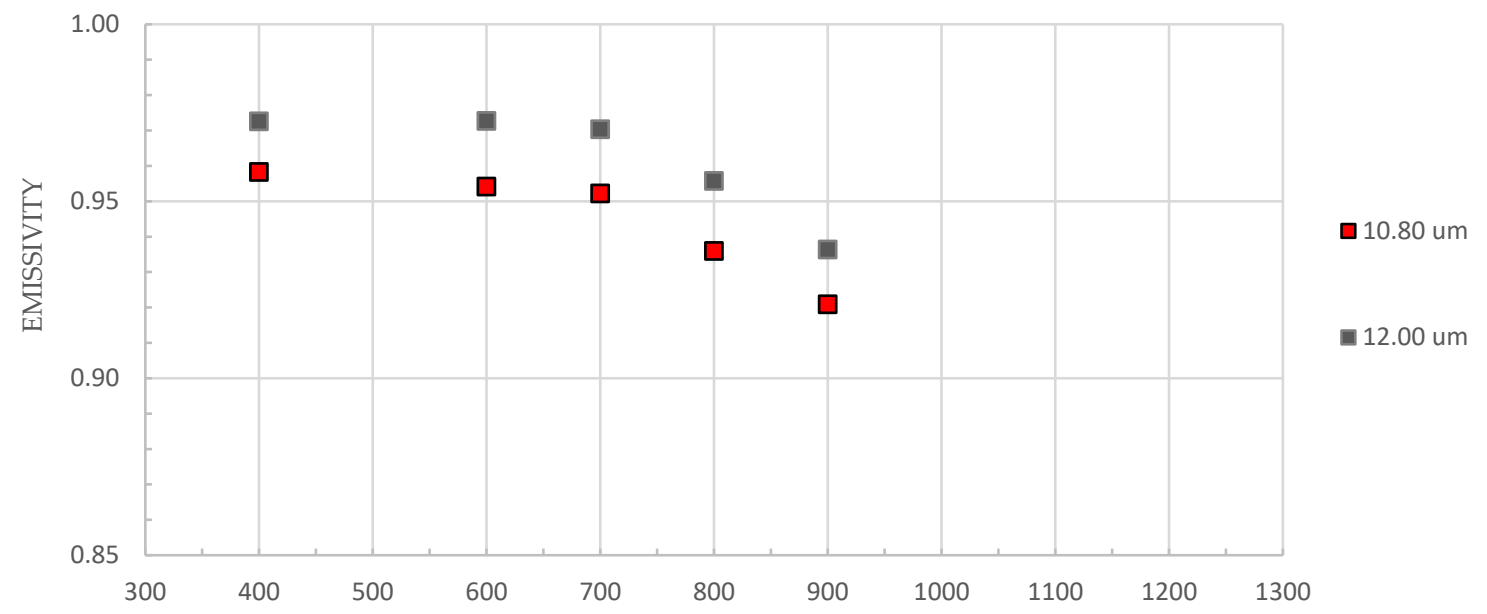

TEMPERATURE (K)

Figure 4. Emissivity variation with temperature increase of 400-900 K shown at Landsat 8 (TIRS) thermal infrared (TIR) bands. 


\subsection{From Spaceborne Data}

Varying the emissivity and wavelength will have an impact on the computation of integrated temperatures and the consequent total radiant heat flux of any high-temperature thermal anomaly investigated.

To perform a quantitative evaluation on the impact of emissivity on computation of lava surface temperatures, we selected two high-spatial (low temporal) resolution images, acquired by Landsat 8 (OLI), during the 2017 eruption on 18 and 27 March.

\subsubsection{High-Spatial (Low-Temporal) Resolution Data}

According to Planck's law, high-temperature thermal anomalies are best observed in SWIR. This region is most sensitive to the temperatures found in an active lava flow (i.e., 900 to $1300 \mathrm{~K}$ ) [22]. According to the Wien's displacement law, the wavelength of maximum radiance shifts to shorter wavelengths with increasing temperature. The temperature of volcanic features varies widely, ranging between 600 and $1500 \mathrm{~K}$, and thus can be observed in TIR, MIR, and SWIR portions of the spectrum. SWIR radiation is mainly emitted in detectable quantities from very hot surfaces (e.g., molten lava), while MIR and TIR detect cooler volcanic surfaces. Hotspot pixels on the ground, within the thermal anomaly are likely to be occupied by more than one temperature component, so an alternative approach is employed, as spaceborne data can provide only integrated pixel temperatures. By applying a fixed threshold test to Landsat 8 OLI's Band 7 radiance, hotspot pixels were detected. To estimate the fraction of cooled (crusted) and/or molten material in each pixel, an analytical approach (e.g., dual band) was employed [23] and shown in Figure 5, for the dates analysed (18 and 27 March 2017). Table 2 compares the total radiant heat flux values calculated using constant emissivity (0.95 and 0.60$)$ values and the 'two-component' approach described in Section 2.3.1.

Table 2. Estimation of total radiant flux $\left(\mathrm{Q}_{\mathrm{R}}\right)$ from Landsat 8 (OLI) data during the 2017 Mt Etna effusive event.

\begin{tabular}{|c|c|c|c|c|}
\hline Date/Time & Emissivity & $(\varepsilon)$ & \# Radiant Pixels & Total Radiant Flux $Q_{R}(\mathrm{GW})$ \\
\hline & Constant & 0.95 & 672 & 3.12 \\
\hline $18 / 03 / 2017$ & Constant & 0.60 & 672 & 3.68 \\
\hline \multirow[t]{2}{*}{ 09:41:54 } & Two & $0.95 *$ & 379 & \\
\hline & Components & $0.60 * *$ & 293 & 3.41 \\
\hline & Constant & 0.95 & 421 & 1.68 \\
\hline $27 / 03 / 2017$ & Constant & 0.60 & 421 & 1.97 \\
\hline \multirow[t]{2}{*}{ 09:35:38 } & Two & $0.95 *$ & 263 & \\
\hline & Components & $0.60 * *$ & 158 & 1.82 \\
\hline
\end{tabular}

\subsubsection{Moderate-to-High Temporal Resolution}

SEVIRI and MODIS data were used here (Figure 6) to analyse the 2017 eruptive activity on Mt Etna, between 14 March and 09 April. The high temporal resolution, with up to five minutes sampling interval in rapid scanning service (RSS) mode, offered by SEVIRI, enables a near-continuous monitoring of volcanic thermal activity. The higher spatial resolution of $1 \mathrm{~km}$ (as opposed to $3 \mathrm{~km}$ for SEVIRI), a good spectral resolution, and high signal-to-noise (STN) ratio offered by MODIS, permits detection of less intense thermal anomalies. For these reasons, both the first and the last thermal anomalies during this eruptive event were detected by MODIS, on 14 March (20:35 GMT) and on 9 April (21:14 GMT), respectively. The peak of activity occurred within the first five days of eruption, with a maximum radiant heat flux of 9.47 gigawatts GW recorded on 17 March (00:40 GMT) by MODIS and 9.67 GW on 18 March (14:15 GMT) by SEVIRI. Thermal activity was quite stable after 20 March 2017, with an 
average radiant heat flux of $\sim 2 \mathrm{GW}$. Converting the radiant heat flux curve into TADR and integrating this information, we obtain the final erupted lava volume of $7.96 \pm 3.5$ million cubic meters.
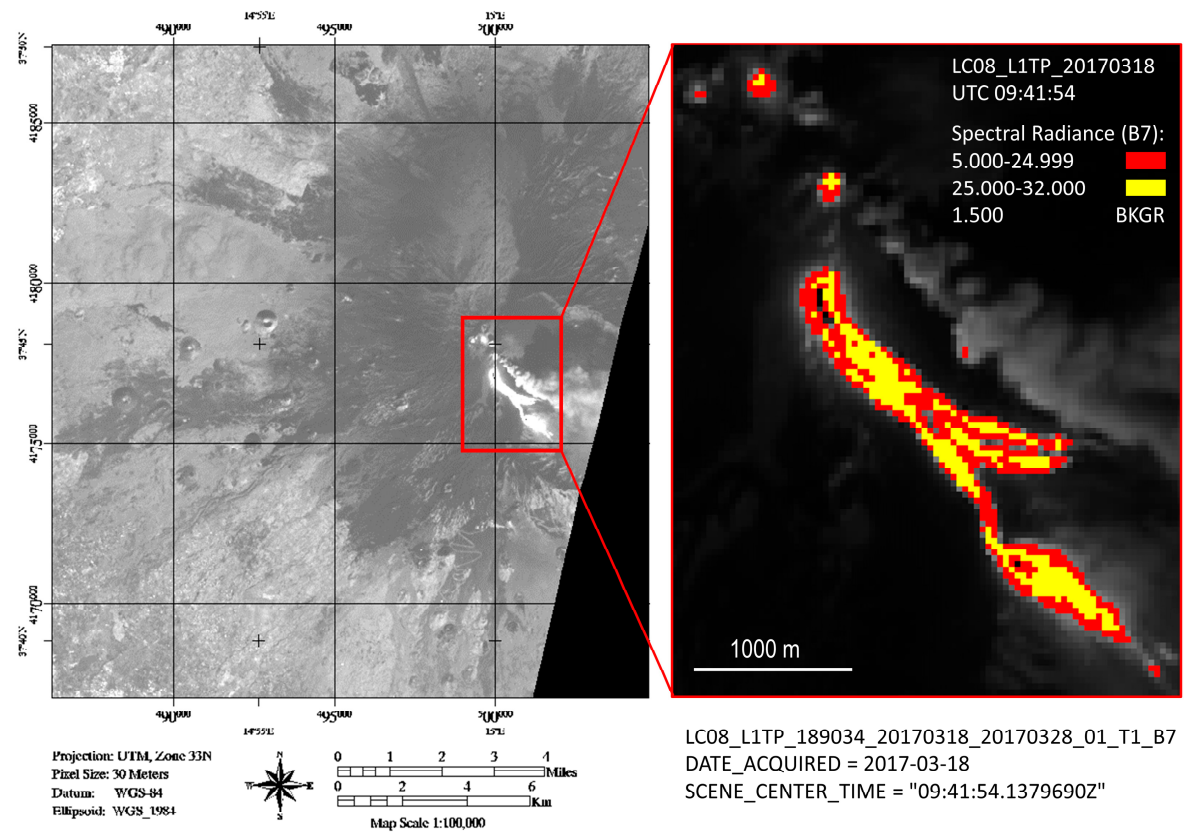

LC08_L1TP_189034_20170318_20170328_01_T1_B7 DATE_ACQUUIRED $=$ 2017-03-18 SCENE_CENTER_TIME = "09:41:54.1379690Z"

(a)
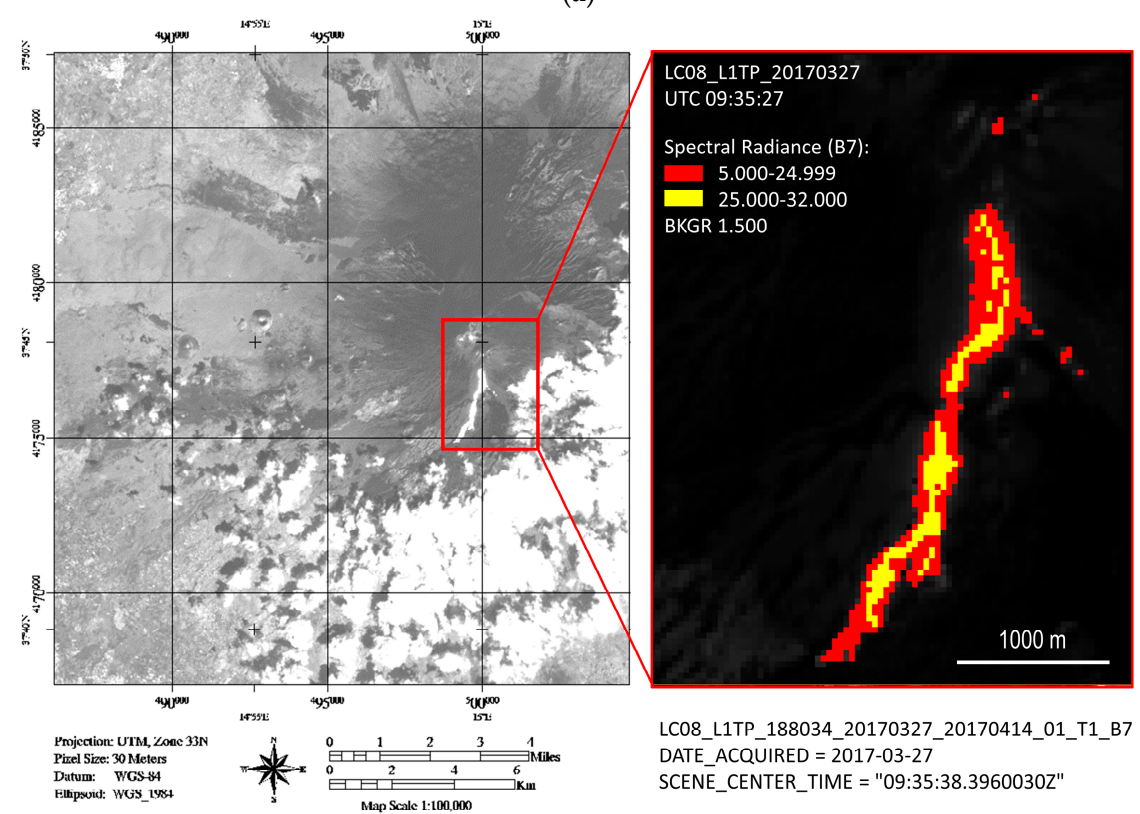

(b)

Figure 5. (a) Effusive activity recorded by Landsat 8 (Operational Land Imager (OLI)) on 18 March 2017 and; (b) 27 March 2017. Following the 'two-component' approach, cut outs in (a,b) contain 'threshold' values used in this study (Section 2.3.1), based on radiance values, where radiant pixels in red are used for computation of crust temperatures (i.e., emissivity 0.95) and radiant pixels in yellow, relating to the melt temperatures (i.e., emissivity 0.60). Background (BKGR) value (averaged radiance value of the pixels surrounding thermally anomalous pixels) was subtracted from radiance data (all thermally anomalous pixels), so that thermal component alone (excluding reflected radiances of daytime images in short-wave infrared (SWIR)) can be analysed. 


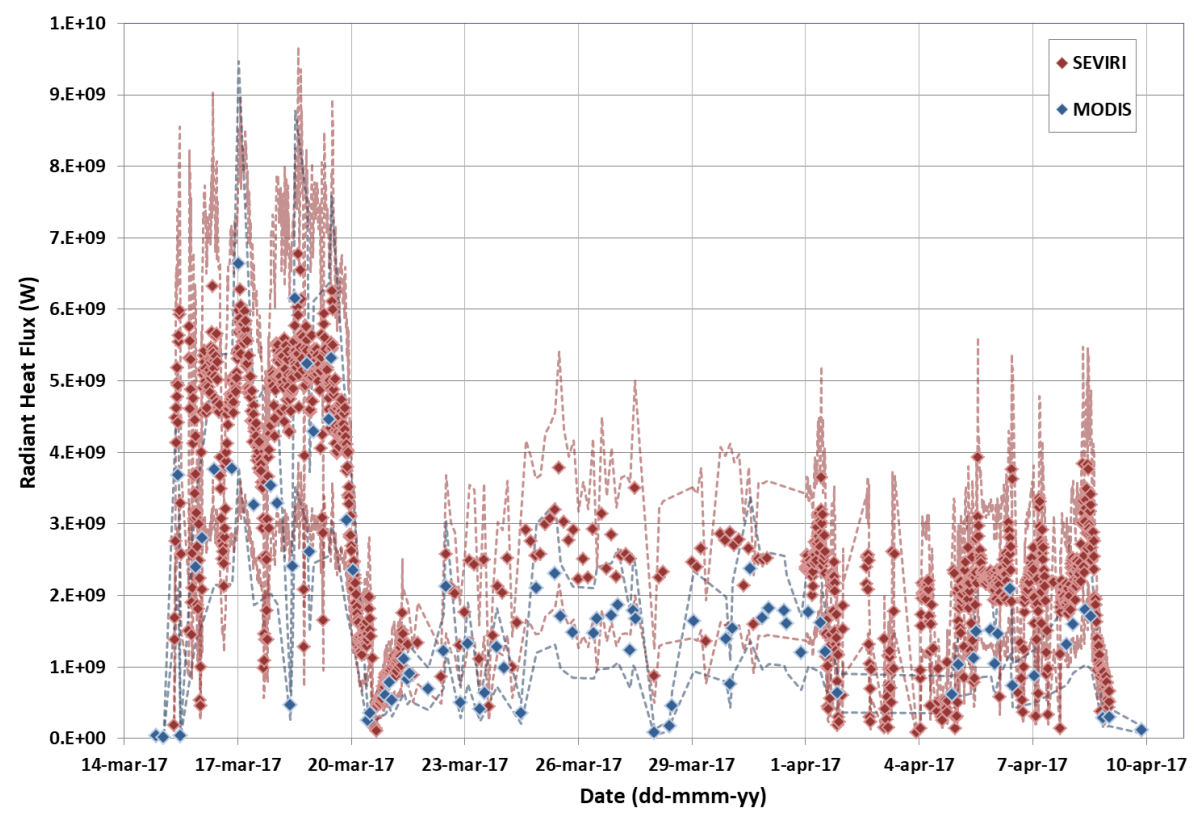

Figure 6. Radiant heat flux computed from Spinning Enhanced Visible and Infrared Imager (SEVIRI) (red diamonds) and Moderate Resolution Imaging Spectroradiometer (MODIS) (blue diamonds) data at Mt Etna from 15 March to 9 April 2017. Dashed lines, in the respective colours, include the range of variation of each time series.

\subsubsection{Spaceborne Data Comparison and Validation}

By comparing the radiant heat flux values obtained from moderate-to-high temporal resolution, namely SEVIRI and MODIS, and high-spatial resolution, namely Landsat-8 OLI data, we found that the latter falls inside the region of admissible values retrieved from SEVIRI and MODIS images (Figure 7). Moreover, the fact that the Landsat- 8 results are quite close to the lower boundaries of the SEVIRI and MODIS, suggests $\varepsilon<\varepsilon_{M I R}$.

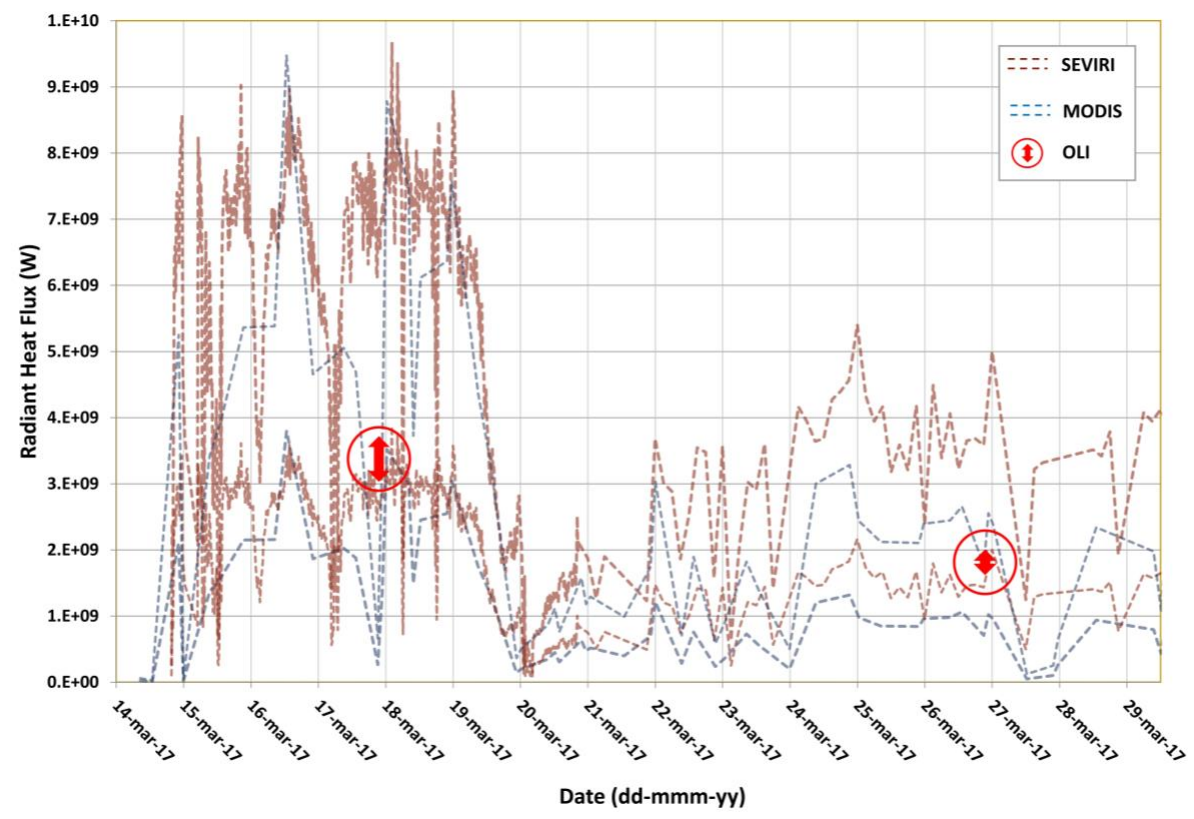

Figure 7. Range of radiant flux variation recorded between 14-29 March 2017 and retrieved by MODIS (blue dashed lines), SEVIRI (purple dashed lines), and Landsat-8 OLI (red circled bars). 


\subsubsection{From Straightforward Modelling}

Figure 8 shows a comparison between the actual lava flow field (white contour outline) and three MAGFLOW simulations run with a constant emissivity of 0.60 (Figure 8a), a constant emissivity of 0.95 (Figure 8b), and with the 'two-component' emissivity approach (Figure 8c).
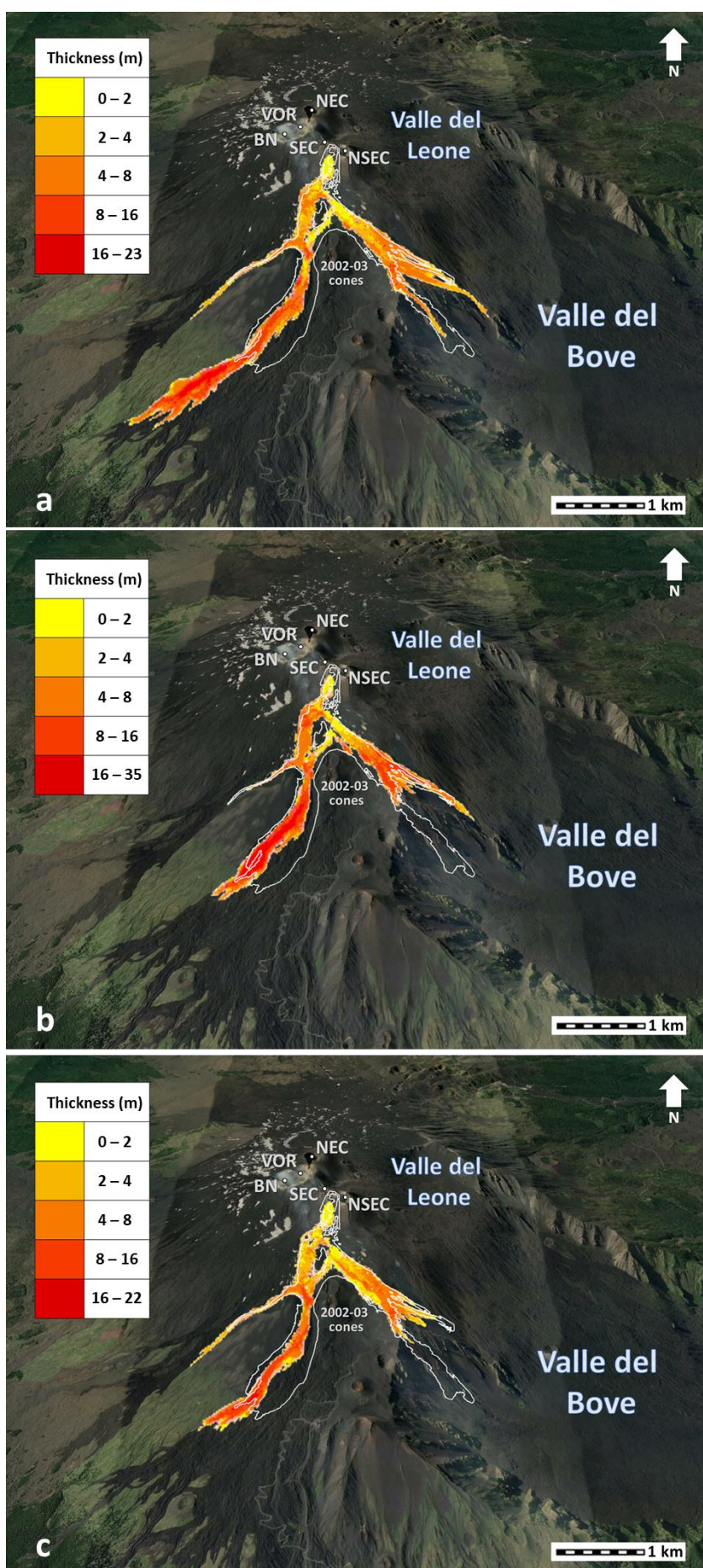

Figure 8. Eruptive scenarios obtained by using a constant emissivity of (a) 0.60 and (b) 0.95 , as well as (c) the 'two-component' emissivity approach. The colours indicate deposit thickness in meters. The white contour highlights the actual lava flow field retrieved from the Sentinel-2A image acquired on 8 April 2017. 
The best simulated scenarios are those run with the constant emissivity of 0.95 and with the 'two-component' emissivity approach. The lava flows modelled, using a constant emissivity of 0.60 , overestimated significantly ( $46 \%$ ) in terms of maximum length, especially for the south-west branch.

This is verified by the accuracy, calculated as the square root of the intersection over union areas of the simulated and actual lava flows [10,62-64]. Although the actual lava flow field is quite well reproduced by all three MAGFLOW simulations with an accuracy always higher than 0.6 , the simulations with the constant emissivity of 0.95 and the 'two-component' emissivity approach reach an accuracy of about 0.7 , against 0.6 reached by the other MAGFLOW simulation.

\section{Discussion}

Land surface temperature (LST) and land surface emissivity (LSE) are two key parameters used in many studies and as satellite input parameters, because they are closely linked to the Earth's surface energy balance [65]. Normally, corrections are needed to estimate LST using spaceborne sensors, such as surface emissivity. If these corrections are neglected, the output data will result in systematic errors.

Remote sensing and laboratory-based FTIR spectroscopy are valuable tools when analysing the same target (or sets of targets) area on the ground. Spaceborne sensor measuring spectral emissivity of a surface can be validated ('ground-truthed') using a laboratory-based thermal emission spectroscopy technique $[61,66]$.

Our laboratory-based FTIR results indicate that emissivity decreases with temperature increase, which is a trend that supports the argument that emissivity of molten material is significantly lower than that of the same material in its solid state [27]. Emissivity results presented here involve a temperature range of 400-900 K, which can be related to cooling and crusted flows. For the molten portion of the flow, we used emissivity values retrieved from literature [25].

The best simulated scenarios using MAGFLOW are those run with the constant emissivity of 0.95 and using the 'two-component' emissivity approach. The lava flows modelled, using a constant emissivity of 0.60 overestimates significantly, in terms of maximum length, especially for the south-west branch. The terrain can attenuate the observed spectral radiance, and hence the LST, because it can act as an obstacle to function of the mutual angle between the sensor plane of the satellite instrument and the normal direction to each cell of the DEM. LSE is an indicator of material composition and can vary with viewing angle and surface roughness. In our case study (i.e., the 2017 Etna eruption), the median slope is about $6^{\circ}$ and there are no shadows due to the topography, so the terrain contribution can be neglected.

Our spaceborne results for both constant emissivity (i.e., 0.95 and 0.60 ) and a 'two-component' approach [25] produced comparable radiant flux results (Table 2), bordering at the lower boundaries of SEVIRI and MODIS acquired values. These indicate a maximum $\leq 16 \%$ variation in calculated total radiant flux between the two emissivity end members (i.e., 0.95 and 0.60). For example, the scene acquired on 18 March 2017 (Table 2) produced a total radiant flux of $3.12 \mathrm{GW}$ using a constant uniform emissivity of 0.95 , and $3.68 \mathrm{GW}$ using an emissivity of 0.60 . Conversely, a 'two-component' emissivity approach produced a total radiant flux value of $3.41 \mathrm{GW}$, perhaps a more realistic value, where two different emissivity values were applied to different components (i.e., crust and melt), expected to be found in an active lava flow.

Furthermore, the variation and magnitude of radiant flux (power) for thermally anomalous pixels gathered by the high-spatial resolution spaceborne data (this study) and MODIS and SEVIRI (this study and [8]), show a marked difference (i.e., overestimation), which may be driven by the difference in spatial resolution (pixel size) and instrument sensitivity capabilities.

Given such data, previous workers have often gone on to calculate lava effusion rates $[67,68]$ or 'distance-to-run' [28]. This is not done here as the high-spatial resolution data are based on a limited number of infrequent observations (scenes), which may or may not correspond to significant peak discharge rates. Equally, research shows [69] that variations in lava effusion rates may occur over short 
timescales, and flow regimes are known to change over timescales of days or less [70-72]. This may suggest that such instantaneous readings might not be truly representative.

Nonetheless, our results highlight the uncertainty in accuracy, as data comparison in this study shows that high-spatial resolution radiant flux results (e.g., from OLI) fall at the lower boundary of values retrieved from MODIS and SEVIRI.

\section{Conclusions}

Laboratory-based FTIR results presented in this study provide a clear indication that the measured emissivity of volcanic samples, investigated here, decreases non-linearly with temperature increase between 400 and $900 \mathrm{~K}$. The current work should now be extended to include higher eruptive temperatures ( $1350 \mathrm{~K}$ for Etna's lavas), using an alternative laboratory-based approach, which would allow heating of samples to this temperature. This is essential to increase our understanding of the behaviour of emissivity at molten rock temperatures. The synergy of high-spatial and high-temporal resolution two-component, radiant flux data has the potential to support more accurate effusion rate estimates, that are critical in supporting operational 'distance-to-run' forecasts. We propose then that the emissivity-temperature relationship be quantified and linked to the range of temperatures found in an active lava flow, by creating a 'Dynamic Emissivity-Temperature Rule'. This would significantly improve the accuracy of lava surface temperatures derivation (from spaceborne data) and operational lava flow forecasting (through modelling applications), which will contribute to hazard assessment and mitigation.

Author Contributions: F.F. and N.R. led the conception and design of the work. N.R., A.C., G.G., and A.M. acquired the data. N.R., A.C., G.G., A.M., and F.F. were responsible for analysis, modelling, and interpretation of data. All authors (N.R., A.C., G.G., A.M., H.R., S.B., and F.F.) participated in drafting and revising the article and have given final approval of the submitted and revised versions.

Funding: The Open University, Milton Keynes, U.K. provided studentship funding for N.R.

Acknowledgments: MAGFLOW simulations were performed within the framework of Tecnolab, the Laboratory for Technological Advance in Volcano Geophysics of the INGV in Catania, Italy. The anonymous reviewers are acknowledged for their constructive and supportive comments, which helped improve this manuscript.

Conflicts of Interest: The authors declare no conflicst of interest. The funders had no role in the design of the study; in the collection, analyses, or interpretation of data; in the writing of the manuscript, or in the decision to publish the results.

\section{References}

1. Sigurdsson, H.; McNutt, S.R.; Rymer, H.; Stix, J.; Houghton, B. The Encyclopedia of Volcanoes, 2nd ed.; Sigurdsson, H., Houghton, B., McNutt, S.R., Rymer, H., Stix, J., Eds.; Academic Press: Cambridge, MA, USA, 2015.

2. Sparks, R.S.; Aspinall, W.P.; Crosweller, H.S.; Hincks, T.K. Risk and Uncertainty Assessment of Volcanic Hazards; 2011; Volume 9781107006, ISBN 9781139047562.

3. Ramsey, M.S.; Harris, A.J.L. Volcanology 2020: How will thermal remote sensing of volcanic surface activity evolve over the next decade? J. Volcanol. Geotherm. Res. 2013, 249, 217-233. [CrossRef]

4. Tait, S.; Ferrucci, F. A real-time, space borne volcano observatory to support decision making during eruptive crises: European volcano observatory space services. In Proceedings of the 2013 UKSim 15th International Conference on Computer Modelling and Simulation, Cambridge, UK, 10-12 April 2013; pp. 283-289.

5. Komorowski, J.C.; Jenkins, S.; Baxter, P.J.; Picquout, A.; Lavigne, F.; Charbonnier, S.; Gertisser, R.; Preece, K.; Cholik, N.; Budi-Santoso, A.; et al. Paroxysmal dome explosion during the Merapi 2010 eruption: Processes and facies relationships of associated high-energy pyroclastic density currents. J. Volcanol. Geotherm. Res. 2013, 261, 260-294. [CrossRef]

6. Pallister, J.; Papale, P.; Eichelberger, J.; Newhall, C.; Mandeville, C.; Nakada, S.; Marzocchi, W.; Loughlin, S.; Jolly, G.; Ewert, J.; et al. Volcano observatory best practices (VOBP) workshops-A summary of findings and best-practice recommendations. J. Appl. Volcanol. 2019, 8. [CrossRef] 
7. Hill, L.J.; Sparks, R.S.; Rougier, J.C. Risk assessment and uncertainty in natural hazards. Risk Uncertain. Assess. Nat. Hazards 2011, 9781107006, 1-18.

8. Cappello, A.; Ganci, G.; Bilotta, G.; Herault, A.; Zago, V.; Del Negro, C. Satellite-driven modeling approach for monitoring lava flow hazards during the 2017 Etna eruption. Ann. Geophys. Geophys. 2018, 61. [CrossRef]

9. Ganci, G.; Cappello, A.; Bilotta, G.; Corradino, C.; Del Negro, C. Satellite-Based Reconstruction of the Volcanic Deposits during the December 2015 Etna Eruption. MDPI J. Data 2019, 4, 120. [CrossRef]

10. Corradino, C.; Ganci, G.; Cappello, A.; Bilotta, G.; Herault, A.; Del Negro, C. Mapping Recent Lava Flows at Mount Etna Using Multispectral Sentinel-2 Images and Machine Learning Techniques. Remote Sens. 2019, 11, 1916. [CrossRef]

11. Cappello, A.; Geshi, N.; Neri, M.; Del Negro, C. Lava flow hazards-An impending threat at Miyakejima volcano, Japan. J. Volcanol. Geotherm. Res. 2015, 308, 1-9. [CrossRef]

12. Cappello, A.; Zanon, V.; Del Negro, C.; Ferreira, T.J.L.; Queiroz, M.G.P.S. Exploring lava-flow hazards at Pico Island, Azores Archipelago (Portugal). Terra Nov. 2015, 27, 156-161. [CrossRef]

13. Bilotta, G.; Cappello, A.; Herault, A.; Ganci, G.; Del Negro, C. MAGFLOW: a physics-based model for the dynamics of lava-flow emplacement. Geol. Soc. Spec. Publ. 2016, 357-373.

14. Del Negro, C.; Cappello, A.; Neri, M.; Bilotta, G.; Hérault, A.; Ganci, G. Lava flow hazards at Mount Etna: Constraints imposed by eruptive history and numerical simulations. Sci. Rep. 2013, 3, 1-8.

15. Del Negro, C.; Cappello, A.; Ganci, G. Quantifying lava flow hazards in response to effusive eruption. Bull. Geol. Soc. Am. 2016, 128, 1-13. [CrossRef]

16. Ramsey, M.; Dehn, J. Spaceborne observations of the 2000 Bezymianny, Kamchatka eruption: The integration of high-resolution ASTER data into near real-time monitoring using AVHRR. J. Volcanol. Geotherm. Res. 2004, 135, 127-146. [CrossRef]

17. Solikhin, A.; Thouret, J.C.; Gupta, A.; Harris, A.J.L.; Liew, S.C. Geology, tectonics, and the 2002-2003 eruption of the Semeru volcano, Indonesia: Interpreted from high-spatial resolution satellite imagery. Geomorphology 2012, 138, 364-379. [CrossRef]

18. Wright, R.; Flynn, L.P.; Garbeil, H.; Harris, A.J.L.; Pilger, E. MODVOLC: Near-real-time thermal monitoring of global volcanism. J. Volcanol. Geotherm. Res. 2004, 135, 29-49. [CrossRef]

19. Wooster, M.J.; Rothery, D.A. Time-series analysis of effusive volcanic activity the using ERS Along Track Scanning Radiometer: The 1995 eruption of Fernandina Volcano, Galapagos Islands. Remote Sens. Environ. 1997, 62, 109-117. [CrossRef]

20. Oppenheimer, C. Thermal distributions of hot volcanic surfaces constrained using three infrared bands of remote sensing data. Geophys. Res. Lett. 1993, 20, 431-434. [CrossRef]

21. Harris, A.; Steffke, A.; Calvari, S.; Spampinato, L. Thirty years of satellite-derived lava discharge rates at Etna: Implications for steady volumetric output. J. Geophys. Res. Solid Earth 2011, 116, 1-15. [CrossRef]

22. Harris, A.J.L. Thermal Remote Sensing of Active Volcanoes: A User's Manual; Cambridge University Press: Cambridge, UK, 2013; Volume 9780521859, ISBN 9781139029346.

23. Hirn, B.; Di Bartola, C.; Ferrucci, F. Spaceborne monitoring 2000-2005 of the Pu'u 'O'o-Kupaianaha (Hawaii) eruption by synergetic merge of multispectral payloads ASTER and MODIS. IEEE Trans. Geosci. Remote Sens. 2008, 46, 2848-2856. [CrossRef]

24. Rothery, D.A.; Francis, P.W.; Wood, C.A. Volcano monitoring using short wavelength infrared data from satellites. J. Geophys. Res. 1988, 93, 7993-8008. [CrossRef]

25. Ramsey, M.; Chevrel, M.; Coppola, D.; Harris, A. The influence of emissivity on the thermo-rheological modeling of the channelized lava flows at Tolbachik volcano. Ann. Geophys. 2019, 61. [CrossRef]

26. Marchese, F.; Neri, M.; Falconieri, A.; Lacava, T.; Mazzeo, G.; Pergola, N.; Tramutoli, V. The contribution of multi-sensor infrared satellite observations to monitor Mt. Etna (Italy) Activity during May to August 2016. Remote Sens. 2018, 10, 1948. [CrossRef]

27. Lee, R.J.; Ramsey, M.S.; King, P.L. Development of a new laboratory technique for high-temperature thermal emission spectroscopy of silicate melts. J. Geophys. Res. Solid Earth 2013, 118, 1968-1983. [CrossRef]

28. Rogic, N.; Cappello, A.; Ferrucci, F. Role of Emissivity in Lava Flow 'Distance-to-Run' Estimates from Satellite-Based Volcano Monitoring. Remote Sens. 2019, 11, 662. [CrossRef]

29. Cappello, A.; Bilotta, G.; Neri, M.; Del Negro, C. Probabilistic modeling of future volcanic eruptions at Mount Etna. J. Geophys. Res. Solid Earth 2013, 118, 1925-1935. [CrossRef] 
30. Cappello, A.; Ganci, G.; Bilotta, G.; Corradino, C.; Hérault, A.; Del Negro, C. Changing Eruptive Styles at the South-East Crater of Mount Etna: Implications for Assessing Lava Flow Hazards. Front. Earth Sci. 2019, 7, 1-10. [CrossRef]

31. Del Negro, C.; Currenti, G.; Napoli, R.; Vicari, A. Volcanomagnetic changes accompanying the onset of the 2002-2003 eruption of Mt. Etna (Italy). Earth Planet. Sci. Lett. 2004, 229, 1-14. [CrossRef]

32. Giordano, D.; Dingwell, D.B. Viscosity of hydrous Etna basalt: Implications for Plinian-style basaltic eruptions. Bull. Volcanol. 2003, 65, 8-14. [CrossRef]

33. Maturilli, A.; Helbert, J.; D’ Amore, M.; Varatharajan, I.; Rosas Ortiz, Y. The Planetary Spectroscopy Laboratory (PSL): wide spectral range, wider sample temperature range. Infrared Remote Sens. Instrum. 2018, 11.

34. Maturilli, A.; Helbert, J. Characterization, testing, calibration, and validation of the Berlin emissivity database. J. Appl. Remote Sens. 2014, 8. [CrossRef]

35. World Metheorological Organisation Observing Systems Capability Analysis and Review Tool—Landsat 8. Available online: https://www.wmo-sat.info/oscar/satellites/view/227 (accessed on 25 September 2019).

36. U.S. Department of the Interior. U.S. Geological Survey Global Visualisation (GloVis) Viewer. Available online: https://glovis.usgs.gov/ (accessed on 1 September 2019).

37. Barsi, J.A.; Barker, J.L.; Schott, J.R. An Atmospheric Correction Parameter Calculator for a Single Thermal Band Earth-Sensing Instrument. Int. Geosci. Remote Sens. Symp. 2003, 5, 3014-3016.

38. Barsi, J.A.; Barker, J.L.; Schott, J.R. Web-Based Atmospheric Correction Tool for Single Thermal Band Instrument. Available online: https://atmcorr.gsfc.nasa.gov/ (accessed on 25 September 2019).

39. Barsi, J.A.; Schott, J.R.; Palluconi, F.D.; Hook, S.J. Validation of a web-based atmospheric correction tool for single thermal band instruments. Earth Obs. Syst. X 2005, 5882, 58820E.

40. Dozier, J. A method for satellite identification of surface temperature fields of subpixel resolution. Remote Sens. Environ. 1981, 11, 221-229. [CrossRef]

41. Francis, P.W.; Rothery, D.A. Using the Landsat Thematic Mapper to detect and monitor active volcanoes: an example from Lascar volcano, northern Chile. Geology 1987, 15, 614-617. [CrossRef]

42. Glaze, L.; Francis, P.W.; Rothery, D.A. Measuring thermal budgets of active volcanoes by satellite remote sensing. Nature 1989, 338, 144-146. [CrossRef]

43. Flynn, L.P.; Harris, A.J.L.; Wright, R. Improved identification of volcanic features using Landsat 7 ETM+. Remote Sens. Environ. 2001, 78, 180-193. [CrossRef]

44. Pieri, D.C.; Glaze, L.S.; Abrams, M.J. Thermal radiance observations of an active lava flow during the June 1984 eruption of Mount Etna. Geology 1990, 18, 1018-1022. [CrossRef]

45. Wright, R.; Pilger, E. Radiant flux from Earth's subaerially erupting volcanoes. Int. J. Remote Sens. 2008, 29, 6443-6466. [CrossRef]

46. USGS Landsat 8 Data Users Handbook. Available online: https://www.usgs.gov/land-resources/nli/landsat/ landsat-8-data-users-handbook (accessed on 1 November 2019).

47. Ganci, G.; Bilotta, G.; Cappello, A.; Herault, A.; Del Negro, C. HOTSAT: A multiplatform system for the thermal monitoring of volcanic activity using satellite data. Geol. Soc. Spec. Publ. 2016, 426, 207-221. [CrossRef]

48. Ganci, G.; Vicari, A.; Fortuna, L.; del Negro, C. The HOTSAT volcano monitoring system based on combined use of SEVIRI and MODIS multispectral data. Ann. Geophys. 2011, 54, 544-550.

49. Ganci, G.; Vicari, A.; Bonfiglio, S.; Gallo, G.; del Negro, C. A texton-based cloud detection algorithm for MSG-SEVIRI multispectral images. Geomat. Nat. Hazards Risk 2011, 2, 279-290. [CrossRef]

50. Wooster, M.J.; Zhukov, B.; Oertel, D. Fire radiative energy for quantitative study of biomass burning: Derivation from the BIRD experimental satellite and comparison to MODIS fire products. Remote Sens. Environ. 2003, 86, 83-107. [CrossRef]

51. Ramsey, M.S.; Harris, A.J.L. Modelling the thermal and infrared spectral properties of active vents: Comparing basaltic lava flows of Tolbachik, Russia to Arsia Mons, Mars. In Proceedings of the AGU Fall Meeting, San Francisco, CA, USA, 12-16 December 2016.

52. Lee, R.J.; Ramsey, M.S. What is the emissivity of active basaltic lava flows? In Proceedings of the AGU Fall Meeting, San Francisco, CA, USA, 12-16 December 2016.

53. Lee, R.J.; King, P.L.; Ramsey, M.S. Spectral analysis of synthetic quartzofeldspathic glasses using laboratory thermal infrared spectroscopy. J. Geophys. Res. Solid Earth 2010, 115, n/a-n/a. [CrossRef] 
54. Ganci, G.; Vicari, A.; Cappello, A.; Del Negro, C. An emergent strategy for volcano hazard assessment: From thermal satellite monitoring to lava flow modeling. Remote Sens. Environ. 2012, 119, 197-207. [CrossRef]

55. Bilotta, G.; Rustico, E.; Hérault, A.; Vicari, A.; Russo, G.; del Negro, C.; Gallo, G. Porting and optimizing MAGFLOW on CUDA. Ann. Geophys. 2011, 54, 580-591.

56. Vicari, A.; Ganci, G.; Behncke, B.; Cappello, A.; Neri, M.; Del Negro, C. Near-real-time forecasting of lava flow hazards during the 12-13 January 2011 Etna eruption. Geophys. Res. Lett. 2011, 38, 1-7. [CrossRef]

57. Vicari, A.; Bilotta, G.; Bonfiglio, S.; Cappello, A.; Ganci, G.; Hérault, A.; Rustico, E.; Gallo, G.; del Negro, C. Lav@hazard: A web-gis interface for volcanic hazard assessment. Ann. Geophys. 2011, 54, 662-670.

58. Ganci, G.; Cappello, A.; Bilotta, G.; Herault, A.; Zago, V.; Del Negro, C. Mapping volcanic deposits of the 2011-2015 etna eruptive events using satellite remote sensing. Front. Earth Sci. 2018, 6, 1-12. [CrossRef]

59. Ganci, G.; Cappello, A.; Zago, V.; Bilotta, G.; Hérault, A.; Del Negro, C. 3D lava flow mapping of the 17-25 may 2016 ETNA eruption using tri-stereo optical satellite data. Ann. Geophys. 2019, 62, 1-6. [CrossRef]

60. French Institut Géographique National MicMac Photogrammetric Library. Available online: http://micmac. ensg.eu (accessed on 1 November 2019).

61. Hamilton, V.E.; Wyatt, M.B.; McSween, H.Y.; Christensen, P.R. Analysis of terrestrial and Martian volcanic compositions using thermal emission spectroscopy 2. Application to Martian surface spectra from the Mars Global Surveyor Thermal Emission Spectrometer. J. Geophys. Res. E Planets 2001, 106, 14733-14746. [CrossRef]

62. Kereszturi, G.; Cappello, A.; Ganci, G.; Procter, J.; Németh, K.; Del Negro, C.; Cronin, S.J. Numerical simulation of basaltic lava flows in the auckland volcanic field, New Zealand-implication for volcanic hazard assessment. Bull. Volcanol. 2014, 76, 1-17. [CrossRef]

63. Kereszturi, G.; Németh, K.; Moufti, M.R.; Cappello, A.; Murcia, H.; Ganci, G.; Del Negro, C.; Procter, J.; Zahran, H.M.A. Emplacement conditions of the 1256 AD Al-Madinah lava flow field in Harrat Rahat, Kingdom of Saudi Arabia-Insights from surface morphology and lava flow simulations. J. Volcanol. Geotherm. Res. 2016, 309, 14-30. [CrossRef]

64. Bilotta, G.; Cappello, A.; Hérault, A.; Del Negro, C. Influence of topographic data uncertainties and model resolution on the numerical simulation of lava flows. Environ. Model. Softw. 2019, 112, 1-15. [CrossRef]

65. Sobrino, J.A.; Jiménez-Muñoz, J.C.; Sòria, G.; Romaguera, M.; Guanter, L.; Moreno, J.; Plaza, A.; Martínez, P. Land surface emissivity retrieval from different VNIR and TIR sensors. IEEE Trans. Geosci. Remote Sens. 2008, 46, 316-327. [CrossRef]

66. King, P.L.; Ramsey, M.S.; McMillan, P.F.; Swayze, G. Laboratory Fourier transform infrared spectroscopy methods for geologic samples. Infrared Spectrosc. Geochem. Explor. Geochem. Remote Sens. 2004, 33, 57-91.

67. Pieri, D.C.; Baloga, S.M. Eruption Rate, Area, and Length relationships for some Hawaiian lava flows. J. Volcanol. Geotherm. Res. 1986, 30, 29-45. [CrossRef]

68. Wright, R.; Blake, S.; Harris, A.J.L.; Rothery, D.A. A simple explanation for the space-based calculation of lava eruption rates. Earth Planet. Sci. Lett. 2001, 192, 223-233. [CrossRef]

69. Bailey, J.E.; Harris, A.J.L.; Dehn, J.; Calvari, S.; Rowland, S.K. The changing morphology of an open lava channel on Mt. Etna. Bull. Volcanol. 2006, 68, 497-515. [CrossRef]

70. Wadge, G. The variation of magma discharge during basaltic eruptions. J. Volcanol. Geotherm. Res. 1981, 11, 139-168. [CrossRef]

71. Harris, A.J.L.; Murray, J.B.; Aries, S.E.; Davies, M.A.; Flynn, L.P.; Wooster, M.J.; Wright, R.; Rothery, D.A. Effusion rate trends at Etna and Krafla and their implications for eruptive mechanisms. J. Volcanol. Geotherm. Res. 2000, 102, 237-269. [CrossRef]

72. Lautze, N.C.; Harris, A.J.L.; Bailey, J.E.; Ripepe, M.; Calvari, S.; Dehn, J.; Rowland, S.K.; Evans-Jones, K. Pulsed lava effusion at Mount Etna during 2001. J. Volcanol. Geotherm. Res. 2004, 137, 231-246. [CrossRef]

(C) 2019 by the authors. Licensee MDPI, Basel, Switzerland. This article is an open access article distributed under the terms and conditions of the Creative Commons Attribution (CC BY) license (http://creativecommons.org/licenses/by/4.0/). 